\title{
Research and design of a robot for pruning street trees
}

Vinh D. Dao*, Nga T. K. Tran, Phuc T. Nguyen, \& Khoa D. Nguyen

Faculty of Engineering and Technology, Nong Lam University, Ho Chi Minh City, Vietnam

\author{
ARTICLE INFO \\ Research Paper \\ Received: July 18, 2018 \\ Revised: October 03, 2018 \\ Accepted: November 23, 2018 \\ Keywords \\ Pruning \\ Robot \\ Trimming

\section{${ }^{*}$ Corresponding author} \\ Dao Duy Vinh \\ Email: duyvinh@hcmuaf.edu.vn
}

ABSTRACT

Trees are planted on street to improve the general landscapes. The landscape's original design is manually maiternaned by the workers. Thus, a robot that can assit workers in trimming the trees is necessary. A self-propelled robot has been developed in order to reduce the risk to humans. The new developed robot would trim uo to $1180 \mathrm{~m}^{2}$ of tree contour when the speed is set at $1 \mathrm{~km} / \mathrm{h}$. This robot can follow the road contour and trim tree automatically.

Cited as: Dao, V. D., Tran, N. T. K., Nguyen P. T., \& Nguyen, K. D. (2019). Research and design of a robot for pruning street trees. The Journal of Agriculture and Development 18(1), 18-25. 


\title{
Nghiên cứu, thiết kế chế tạo Robot cắt tỉa tự động viền cây xanh đường phố
}

\author{
Đào Duy Vinh*, Trần Thị Kim Ngà, Nguyễn Tấn Phúc \& Nguyễn Đăng Khoa \\ Khoa Cơ Khí Công Nghệ, Trường Đại Học Nông Lâm TP. Hồ Chí Minh, TP. Hồ Chí Minh
}

THÔNG TIN BÀI BÁO
Bài báo khoa học
Ngày nhận: 18/07/2018
Ngày chînh sửa: 03/10/2018
Ngày chấp nhận: 23/11/2018
Từ khóa
Cắt tỉa
Robot
Tỉa cây
*Tác giả liên hệ
Đào Duy Vinh
Email: duyvinh@hcmuaf.edu.vn

\section{THÔNG TIN BÀI BÁO}

\section{TÓM TẮT} Nhân công thường xuyên phải cắt tỉa để giữ cảnh quan không bị phá vỡ cấu trúc thiết kế. Có rất nhiều loại máy cầm tay được thiết kế hỗ trợ công nhân tỉa cây. Tuy nhiên công việc này thường phải thực hiện ngay giữa đường, rất nguy hiểm. Để giảm rũi ro cho con người, đã chế tạo một Robot tự hành tỉa viền cây xanh đường phố, với năng suất cắt tỉa được $1180 \mathrm{~m}^{2}$ bề mặt viền cây khi tốc độ Robot di chuyển 1 $\mathrm{km} /$ giờ. Robot tự bám bệ xi măng trên đường và cắt tỉa ba mặt của viền cây xanh một cách tự động.
Ngày nay, cảnh quan đường phố được xây dựng ngày càng hiện đại.

\section{1. Đặt Vấn Đề}

Hiện nay, diện tích công viên đô thị công cộng riêng Thành phố Hồ Chí Minh, khu vực 12 quận cũ là 235 ha, 5 quận mới và khu vực ngoại vi khoảng 2.497 ha. Để duy trì mỹ quan đô thị công nhân thường xuyên chăm sóc và bảo vệ bố cục thiết kế ban đầu. Để thực hiện tỉa viền cây xanh, hầu hết là nhân công dùng kéo tay thao tác, rất tốn nhiều thời gian và kinh phí. Công việc này ảnh hưởng tới sức khỏe bởi tiếng ồn khói bụi khi phải làm giữa đường có xe qua lại.

Hiện nay đã có một số nghiên cứu thiết bị phục vụ cho công việc tỉa cây tuy nhiên qui mô không phù hợp với điều kiện Việt Nam. Hình 1a bộ phận công tác được gắn trên máy kéo. Trong nước đã có một số mô hình hỗ trợ việc tỉa cây tuy nhiên vẫn phải cần con người đẫy trực tiếp giữa công trường (Hình 1b).

Kết quả hình dáng hàng cây sau tỉa phụ thuộc rất nhiều vào tay nghề của người thực hiện. Chi phí cho việc tỉa viền cây rất lớn và công việc này thường xuyên thực hiện. Để hình dáng viền cây sau tỉa không còn lệ thuộc vào tay nghề công

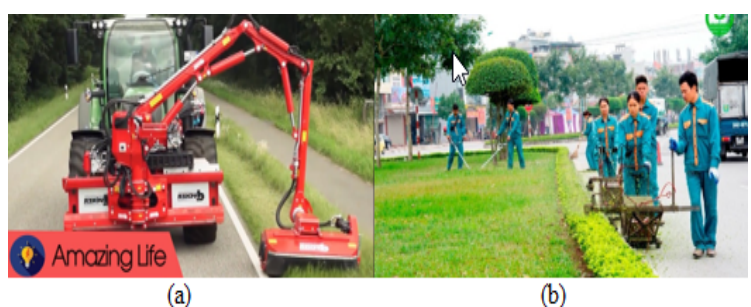

(a)
Hình 1. Một số phương pháp tỉa viền cây hiện nay.

nhân thực hiện và bớt nặng nhọc cho người lao động phải thao tác giữa đường. Cần thiết kế chế tạo Robot tự cắt tỉa viền cây xanh một cách tự động.

\section{Vật Liệu và Phương Pháp Nghiên Cứu}

\subsection{Vật liệu}

Robot được thiết kế và chế tạo thử nghiệm tại xưởng thực hành ở khoa Cơ khí Công nghệ. Các chi tiết được thiết kế và gia công dưới sự hỗ trợ của tổ gia công CNC. Vận hành thí nghiệm Robot được tiến hành trên hàng viền cây Ác ó, 
tại khu công viên trên đường dẫn vào khu giảng đường Phượng Vỹ - Trường Đại học Nông Lâm TP.HCM.

\subsection{Phương pháp nghiên cứu}

Phân tích, lựa chọn các phương pháp thiết kế hệ dẫn động của Robot. Từ đó chọn lựa kết cấu dẫn động với yêu cầu: Robot có bán kính quay vòng nhỏ và chi phí năng lượng cho việc chạy và bẻ lái tối ưu. Động cơ dẫn động thân robot và các động cơ tỉa ngọn cây ở các mặt được chọn lựa loại DC có chổi than và được cung cấp phổ biến trên thị trường. Sử dụng phương pháp điều khiển vòng kín có tín hiệu hồi tiếp của Encoder phối hợp với giải thuật PID để điều khiển và giám sát tốc độ di chuyển của Robot.

\section{Kết Quả và Thảo Luận}

Thông số kỹ thuật của Robot tỉa viền cây thể hiện ở Bảng 1.

\subsection{Thiết kế phần cơ khí}

Hiện nay có rất nhiều phương pháp để thiết kế hệ dẫn động cho thân Robot được thể hiện ở Hình 2 và Bảng 2, tuy nhiên tương ứng với mỗi trường hợp có ưu nhược điểm khác nhau. Mục tiêu của việc thiết kế Robot là chọn được kết cấu đáp ứng được yêu cầu hoạt động với chi phí tiêu hao năng lượng thấp nhất có thể. Các loại kết cấu dẫn động rô bốt tham khảo theo Goris (2005).

Phương án f: Robot sử dụng chuyển động tương đối của 2 bánh chủ động phía sau để bẻ lái. Bánh trước sử dụng là dạng bánh tự lựa. Tuy nhiên, khung xe thường mất ổn định khi chạy nhanh; trường hợp di chuyển chậm thì không ảnh hưởng. Loại hình này chi phí năng lượng rất thấp. Bán kính quay vòng rất nhỏ phù hợp với tiêu chí nghiên cứu (Hình 3).

Robot cắt tỉa viền cây được thiết kế và mô phỏng $3 \mathrm{D}$ bằng phần mểm SolidWorks, nguyên lý hoạt động của Robot cắt tỉa viền cây được thể hiện ở Hình 4. Khung Robot phải có độ cứng vững để tải khối lượng bình ắc qui và lực cản khi cắt. Phần khung được thiết kế bằng thép tấm dày 3 mm; được chấn định hình dạng chữ U. Phần bao che phía trên được chế tạo bằng thép tấm dày 1,2 $\mathrm{mm}$.

Nguyên lý làm việc của Robot: Ban đầu Robot được người vận hành di chuyển tới bệ xi măng dưới chân viền cây xanh. Điều chỉnh khoảng cách và cao độ của hai lưỡi cắt theo phương thẳng đứng: Quay núm vặn số (8), rồi dịch chuyển vị trí ra - vào của lưỡi cắt số (9) áp sát mặt trong của viền cây và khóa vị trí lưỡi cắt mặt trong lại. Tiếp đến vặn núm khóa số (10), sau đó dịch chuyển vị trí dao cắt số (13), ra - vào để cho lưỡi cắt ngoài áp sát bề mặt ngoài của viền cây. Sau khi chỉnh được khoảng cách của hai lưỡi cắt theo phương thẳng đứng phải khóa chặt các núm vặn số (8) và số (10).

Điều chỉnh Độ cao của hai lưỡi cắt theo phương thẳng đứng: Tháo lỏng ốc khóa, quay tay quay số (7) theo chiều kim đồng hồ để nâng hai lưỡi cắt hai bên lên cao. Ngược lại, khi quay tay quay số (7) ngược kim đồng hồ sẽ hạ hai lượi cắt xuống phía dưới. Tùy vào độ cao của bệ xi măng dưới chân viền cây mà ta điều chỉnh độ cao của hai lưỡi cắt hợp lý. Thường thì khoảng cách từ điểm thấp nhất của lưỡi cắt đứng cách bề mặt trên của bệ xi măng 50 mm là hợp lý. Khi độ cao của hai lưỡi bên ở vị trí phù hợp thì phải khóa chặt vị trí bằng các vít hãm.

\subsection{Tính toán, thiết kế kết cấu dao tỉa viền cây}

Vận tốc cắt và góc cắt được tham khảo từ Bui (2004). Xây dựng mô hình toán kết cấu dao cắt tỉa viền cây xanh. Để tạo thành một bộ lưỡi cắt, sử dụng nguyên lý chuyển động điều hòa hình Sin, tạo chuyển động cho hai tấm răng có hình dạng như hình lược. Hai tấm răng hình lược này được bố trí áp sát nhau và có thể chuyển động trược tương đối trên nhau. Nguyên lý hoạt động tương tự như nhiều chiếc kéo nhỏ được đặt liên tiếp nhau. Hai nhánh răng được truyền động cùng một trục quay theo cùng biên độ, chung một chu kỳ $\omega$, và đối xứng nhau nửa chu kỳ chuyển động $\pi$. Nguyên lý này giúp kết cấu vượt qua điểm bắt đầu chu kỳ dễ dàng hơn.

Theo Singiresu (1986), mô hình toán chuyển động kết cấu hai nhánh răng trong lưỡi cắt được thể hiện ở Hình 5. Với các thông số được định nghĩa bao gồm: Biên độ giao động $\mathrm{A}$ được tính toán, chọn lựa phù hợp với hình dạng và khoảng cách của 2 răng liền kề trên tấm răng lược. Tần số quay của động cơ phát lực $\omega$ được thiết kế và điều khiển phù hợp với vận tốc cắt thái. Tấm răng bên trái được gọi là $\mathrm{X}_{1}$ chuyển động với phương trình $\mathrm{X}_{1}=\sin (\omega \mathrm{t})$. Trong khi phần tấm răng bên phải được định nghĩa là $\mathrm{X}_{2}$ chuyển động theo phương trình có dạng $\mathrm{X}_{2}=\sin (\omega \mathrm{t}+\pi)$. 
Bảng 1. Thông số kỹ thuật của Robot tỉa viền cây đã thiết kế

\begin{tabular}{ll}
\hline & Thông số kỹ thuật \\
\hline Kích thướt Robot & $1200 \times 800 \times 800$ \\
Trọng lượng Robot & $67 \mathrm{~kg}$ \\
Chiều cao tối đa có thể tỉa & $500 \mathrm{~mm}$ \\
Loại cây cắt tỉa & Một số loại cây trồng làm viền \\
Vị trí làm việc & Đường phố, công viên \\
Động cơ cắt (1 bộ dao) & DC $100 \mathrm{~W}$ \\
Nguyên lý dao tỉa cành cây & Dạng tông đơ \\
Độ rộng hai dao cắt thay đồi & 200 đến $450(\mathrm{~mm})$ \\
Động cơ điện truyền động & DC $12 \mathrm{~V}$ \\
Năng suất diện tích bề mặt cát tỉa viền cây xanh & $1180 \mathrm{~m}$ /giờ \\
\hline
\end{tabular}

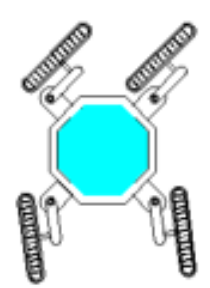

(a)

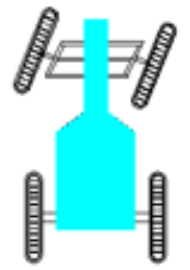

(b)

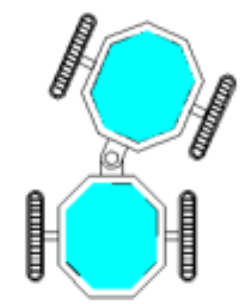

(c)

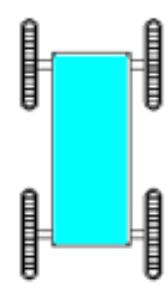

(d)

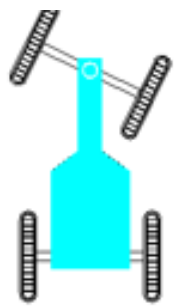

(e)

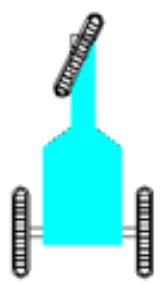

(f)

Hình 2. Các phương pháp điều chỉnh hướng của Robot hay dùng.

Bảng 2. Phương án để thiết kế hệ dẫn động cho thân Robot

\begin{tabular}{cccl}
\hline Phương án & Năng lượng & Bán kính quay vòng & Kiểu dẫn động \\
\hline $\mathrm{a}$ & Cao & Nhỏ & Lái 4 bánh độc lập \\
$\mathrm{b}$ & Thường & Lớn & Kết cấu hình thang lái dẫn hướng \\
$\mathrm{c}$ & Cao & Nhỏ & Gấp khúc giữa thân xe \\
$\mathrm{d}$ & Cao & Lớn & Bánh gắn liền trục thẳng \\
$\mathrm{e}$ & Thấp & Lớn & Lái đồng trục phía trước \\
$\mathrm{f}$ & Thấp & Nhỏ & Lái bằng 2 bánh sau \\
\hline
\end{tabular}

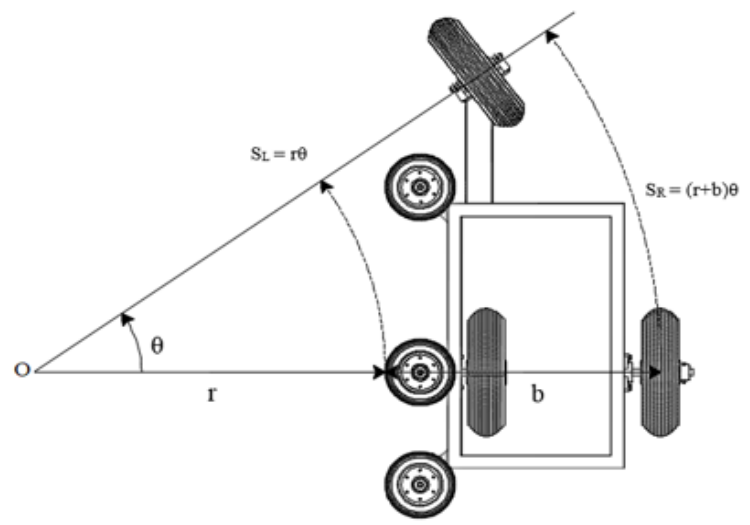

Hình 3. Các góc dịch chuyển khung robot tỉa viền cây.
Thực nghiệm khảo sát lực cắt cần thiết để phá hủy cành cây kích thước giới hạng đường kính nhỏ hơn $6 \mathrm{~mm}$. Khoảng cách từ ngọn đo ngược về thân khảo sát mỗi vị trí lần lượt cách nhau $50 \mathrm{~mm}$. Sử dụng loadcell đo lực cắt cành cây lực cắt do động cơ DC truyền tới lưỡi cắt thông qua kết cấu tay quay con trượt. Giá trị đọc được lưu trên máy tính và vẽ đồ thị diễn biến quá trình cắt Hình 6.

Qua đồ thị ở Hình 6 cho thấy lực cần thiết để phá hủy cành cây Ắc ó cách ngọn 200 mm có đường kính trung bình 5,24 mm. Giá trị cắt cực đại cần $65 \mathrm{~N}$. 

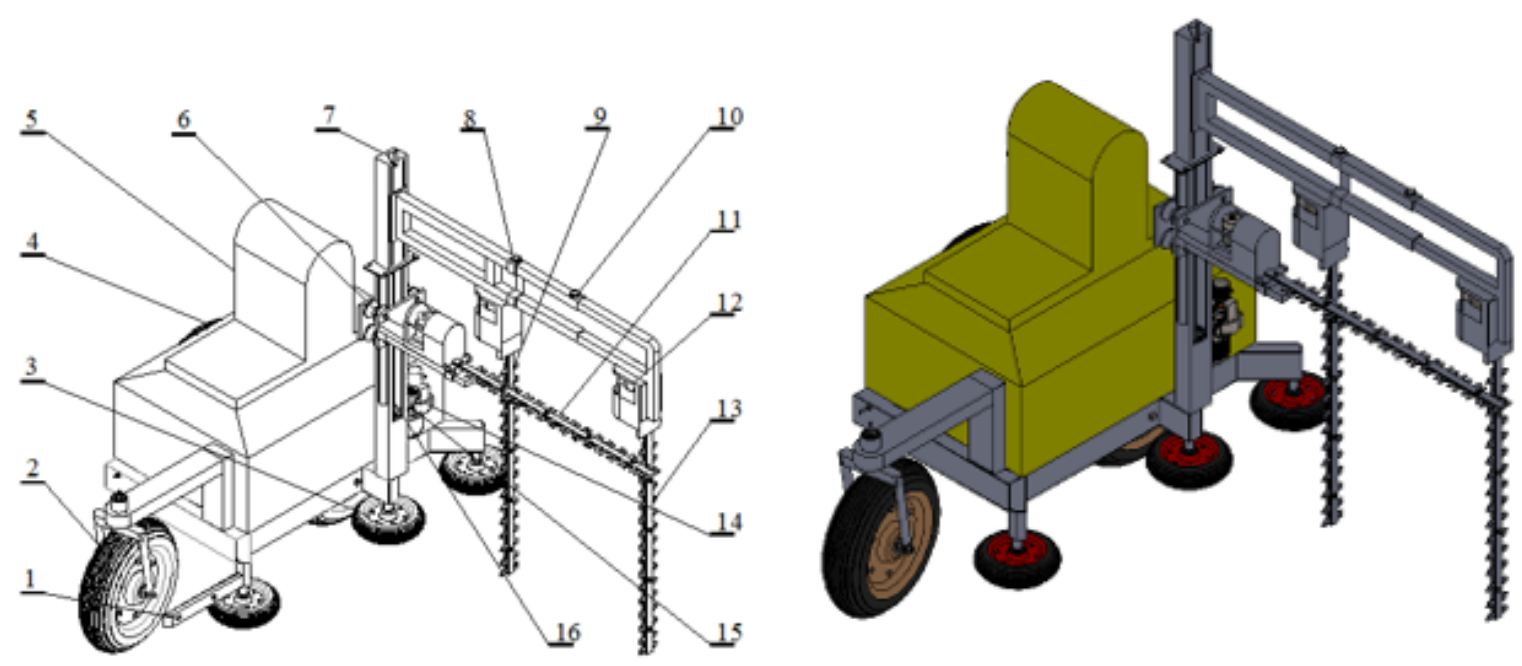

Hình 4. Mô hình Robot tỉa viền cây được thiết bằng phần mềm SolidWorks.
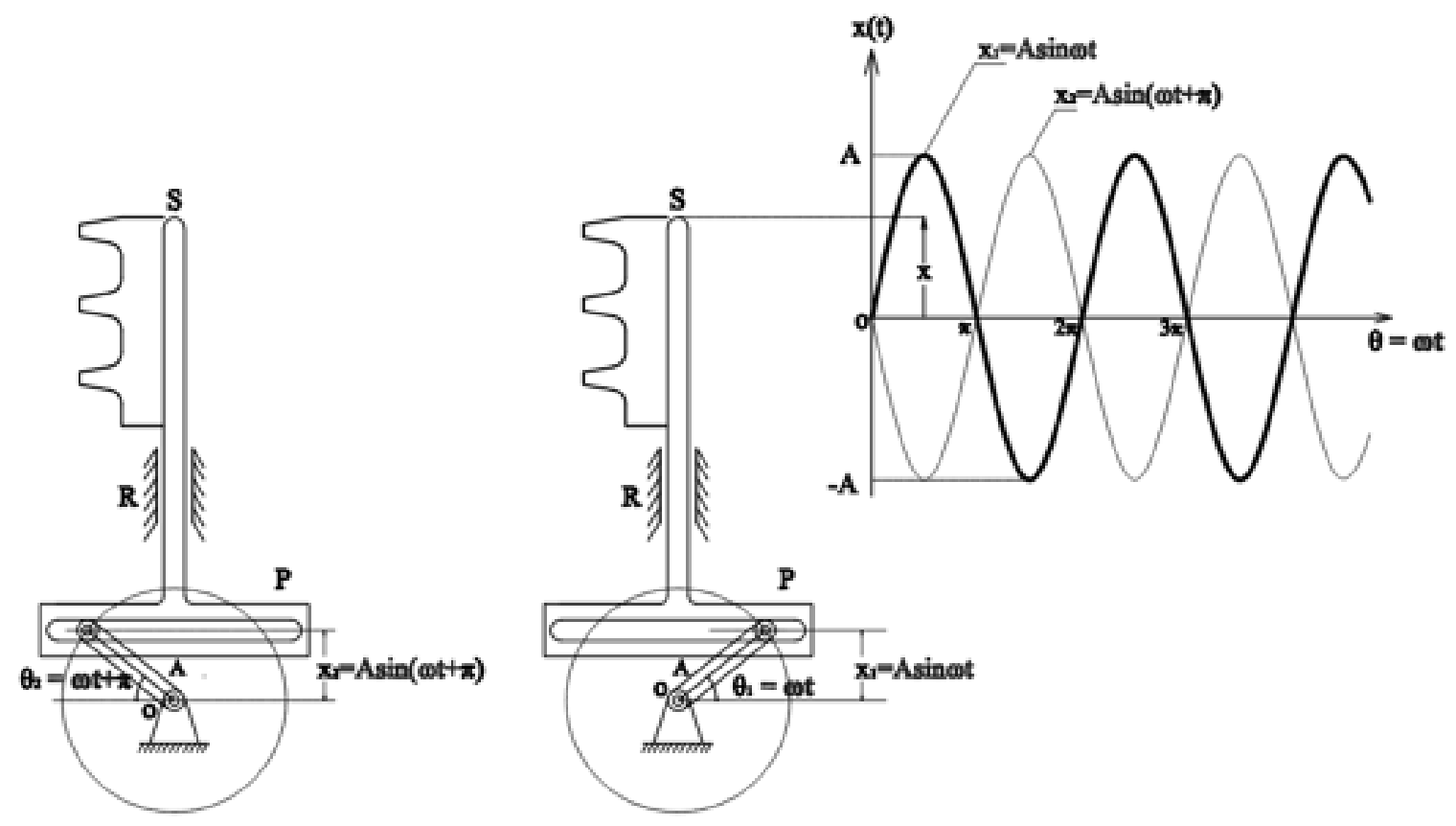

Hình 5. Mô hình toán chuyển động của hai tấm răng lược trong bộ lưỡi cắt tỉa viền cây.

\subsection{Tính toán chọn lựa công suất động cơ điện dẫn động cho Robot}

Để xác định công suất cần thiết của động cơ, ta sử dụng mô Hình 7 công suất động cơ dẫn động của Robot tham khảo từ Junyao \& ctv. (2009).

Xe với khối lượng $m$ được kéo lên một độ dốc $\alpha$ so với chiều ngang. Lực cần thiết để thực hiện được điều đó là $\mathrm{F}_{\mathrm{Kéo}}$ :

$\mathrm{F}_{\text {Kéo }}=\mathrm{F}_{\mathrm{m}}+\mathrm{F}_{\text {Ma sát }}=\mathrm{mg} \cdot \sin \alpha+\mu \mathrm{mg} \cdot \cos \alpha$ $=\operatorname{mg}(\sin \alpha+\mu \cos \alpha)$.

Trong đó:

$\mathrm{F}_{\text {Kéo }}$ : Lực cần thiết để làm Robot di chuyển. $\mathrm{m}$ : Khối lượng của Robot.

$\alpha$ : Góc nghiên so với phương ngang.

$\mu$ : Hệ số ma sát của bánh xe khi lăn. 

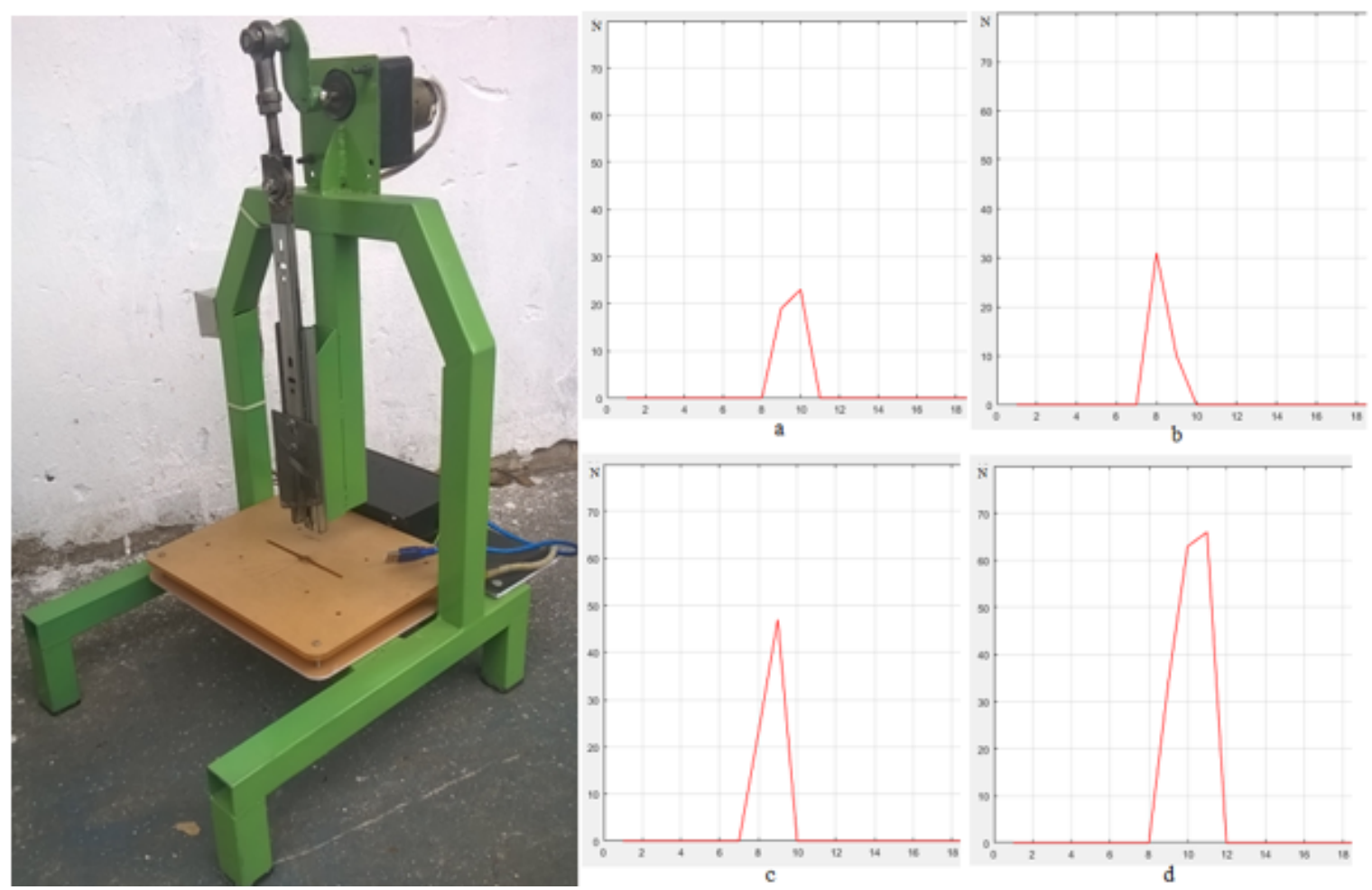

Hình 6. Thí nghiệm đo lực cắt cành cây sử dụng Loadcell.

Giá trị lực ghi nhận khi thực hiện trên cành Ắc ó ở từng vị trí: a) 50 mm; b) 100 mm; c) 150 mm; d) 200 mm tính từ ngọn cây trở về cành.

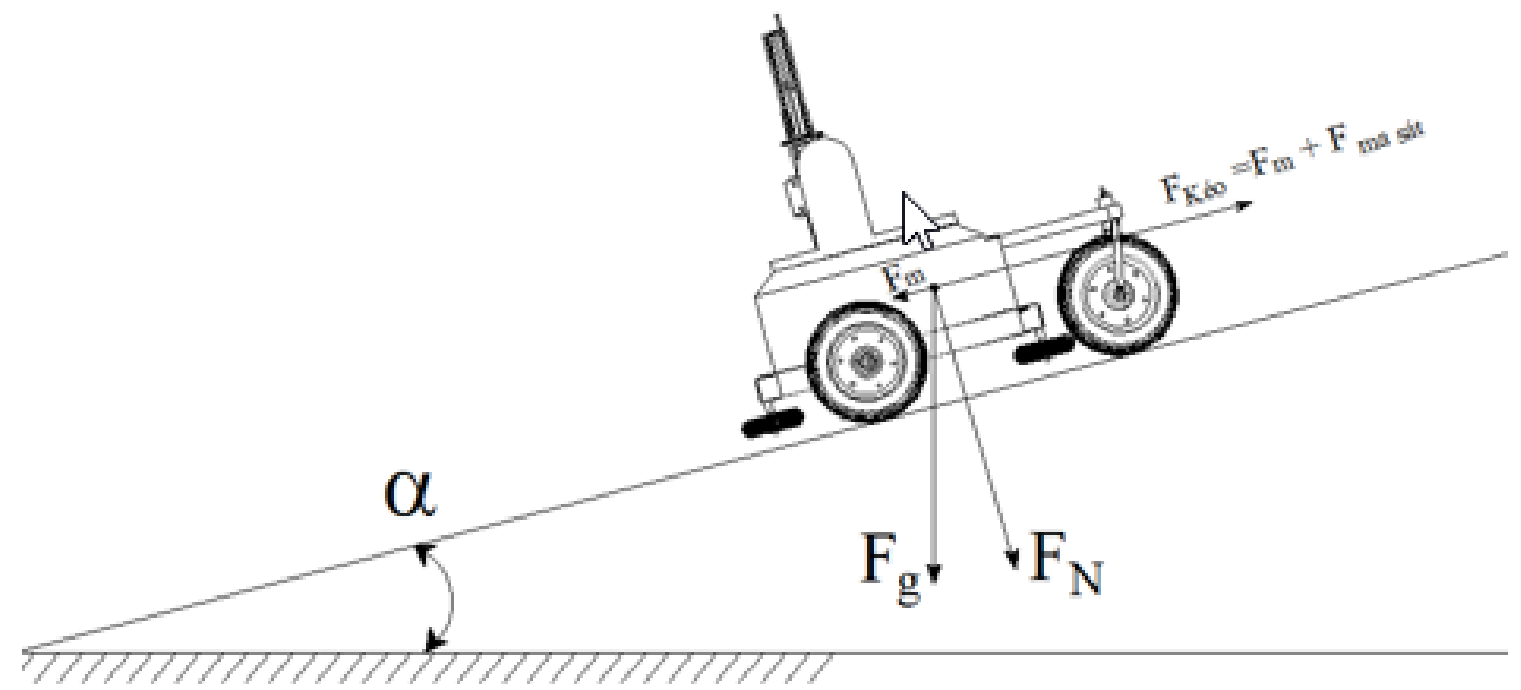

Hình 7. Phân tích lực cần thiết cho động cơ dẫn động trên Robot.

Với $\mathrm{m}=67 \mathrm{~kg}$.

Chọn các thông số theo Goris (2005) có $\alpha=$ 150 và $\mu=0,05$.
Tốc độ trung bình được đề xuất của robot là $1 \mathrm{~km} /$ giờ tương đương $0,28 \mathrm{~m} /$ giây. Để đạt được tốc độ mong muốn ta chọn một tốc độ tối đa gấp 
bốn lần tốc độ trung bình được đề xuất:

$\mathrm{v}_{\max }=4 \times \mathrm{v}=4 \times 0,28=1,12$ (m/giây).

Công suất cần có để robot chạy với tộc độ đề xuất là:

$\mathrm{P}=\mathrm{F}_{\text {Kéo }} \times \mathrm{v}$.

Công suất cực đại có công thức:

$\mathrm{P}_{\max }=\mathrm{F}_{\text {Kéo }} \times \mathrm{v}_{\max }$.

Khi xe chạy với khối lượng $\mathrm{m}$, cần một động cơ có công suất là: W.

$\mathrm{P}_{\max }=\operatorname{mg}(\sin \alpha+\mu \cos \alpha) \times \mathrm{v}_{\max }=221,82$

Dựa vào kết quả tính toán công suất cực đại và tiến hành lựa chọn động cơ phổ biến trên thị trường hiện nay chọn động cơ DC 12 Vôn 250 W.

\subsection{Thiết kế mạch điều khiển Robot tỉa viền cân xanh}

Sơ đồ điều khiển Robot tỉa viề cây xanh được thể hiện ở Hình 8. Các tín hiệu từ cảm biến phát hiện bệ xi măng đưa về mạch điều khiển, xử lý và phát lệnh điều khiển tốc độ động cơ dẫn động. Đảm bảo Robot luôn di chuyển song hành cùng bệ xi măng. Tín hiệu từ Encoder đưa về mạch điều khiển giúp Robot đo và giám sát tốc độ di chuyển.

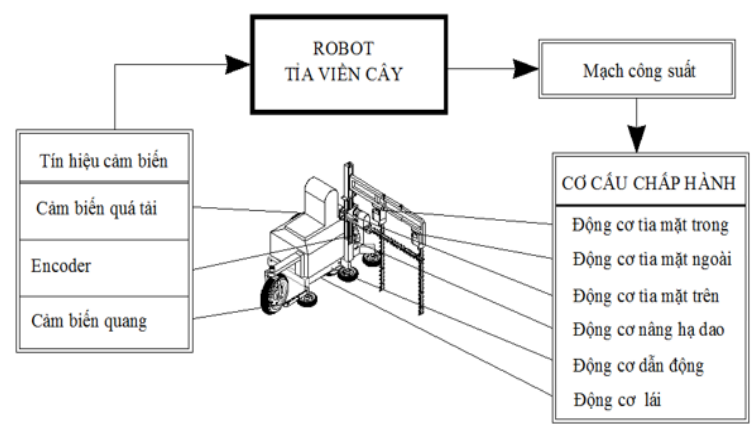

Hình 8. Sơ đồ điều khiển của Robot cắt tỉa viền cây (Tran \& ctv. (2001).

Để điều khiển tốc độ cắt của Robot tỉa viền cây ta cần điều khiển tốc độ của động cơ dẫn động (Hình 9). Khi đi thẳng thì tốc độ của động cơ cần được điều khiển ở tốc độ phù hợp và tương thích với khả năng cắt của dao tỉa cành cây. Vì vậy, tốc độ của động cơ cần phải có sự điều khiển và giám xác. Do đó bộ điều khiển đáp ứng được yêu cầu trên có thể sử dụng bộ điều khiển PID.

Khảo nghiệm khả năng làm việc của Robot: Robot tỉa viền cây được thử nghiệm ngay trên

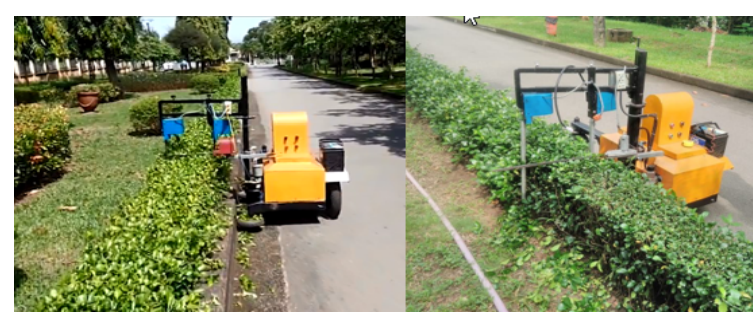

Hình 9. Hình ảnh tỉa thí nghiệm viền cây dùng Robot.

tuyến đường dẫn vào khu giảng đường Phượng Vỹ, Trường Đại học Nông Lâm TP.HCM. Địa chỉ khu phố 6, Phường Linh Trung, Quận Thủ Đức. Mô hình bố trí thí nghiệm được tiến hành như sau: Chọn ngẫu nhiên $10 \mathrm{~m}$ theo chiều dài viền cây. Kẻ nhiều vạch, mỗi vạch cách nhau $1 \mathrm{~m}$. Đo đạt kích thước của các cạnh của viền cây. Hai cạnh bên có chiều cao trung bình 400 mm, kích thước cạnh ngang $380 \mathrm{~mm}$. Diện tích bề mặt dao tỉa cây thực hiện trên mỗi mét chiều dài là 1.18 $\mathrm{m}^{2}$. Cho Robot chạy tự bám bệ xi măng và cắt tỉa viền cây. Khi Robot di chuyển tới mỗi vạch, đọc giá trị trên đồng hồ đếm 1 lần. Thí nghiệm được lập lại nhiều lần sau đó tính ra vận tốc di chuyển của Robot được thể hiện ở Hình 10. Diện tích bề mặt viền cây xanh Robot đã tỉa sau 1 giờ đạt được $1180 \mathrm{~m}^{2}$.

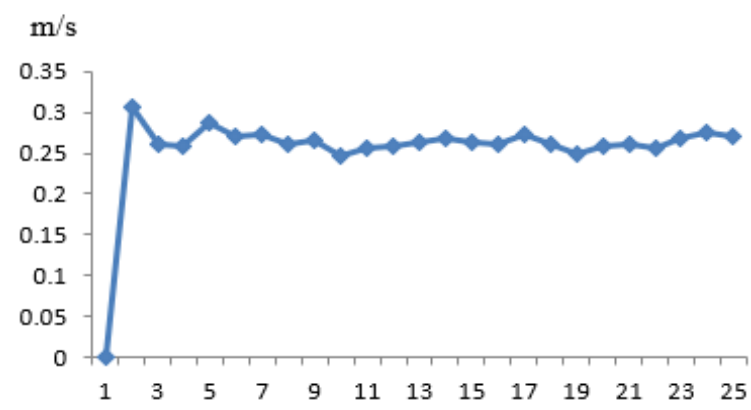

Hình 10. Hình ảnh tỉa thí nghiệm viền cây dùng Robot.

Theo quan sát thực tế khi nhân công dùng máy xạc cỏ để tỉa viền cây Ắc ó. Kích thước viền cây trung bình 3 cạnh của viền cây là $380 \times 380 \times$ 400 mm. Thời gian một nhân công cắt liên tục 10 $\mathrm{m}$ tới theo chiều dài viền cây mất 3 phút. Tương đương nếu nhân công thực hiện liên tục trong 1 giờ sẽ tỉa được khoảng $232 \mathrm{~m}^{2}$ bề mặt viền cây.

Dựa vào kết quả cho thấy rô bốt có năng suất tương đương với 5 đến 6 nhân công lao động sử 
dụng dụng cụ bán thủ công.

\section{Kết Luận}

Đã thiết kế, chế tạo một Robot có thể tự di chuyển dọc theo bệ xi măng của hàng viền cây xanh và cắt tỉa viền cây một cách tự động. Qua kết quả thí nghiệm cho thấy Robot có khả năng tỉa cùng lúc 3 bề mặt của viền cây xanh có kích thước $400 \mathrm{~mm} \times 400 \mathrm{~mm} \times 380 \mathrm{~mm}$, tốc độ di chuyển của Robot tương đương $1 \mathrm{~km} /$ giờ; năng suất đạt được $1180 \mathrm{~m}^{2}$ bề mặt viền cây xanh trên 1 giờ. Có thể điều chỉnh khoảng cách của hai lưỡi cắt thẳng đứng để phù hợp với nhiều bề rộng của viền cây. Robot có thể thay thế người lao động trực tiếp thao tác trên đường. Giảm nặng nhọc cho công nhân cắt giữa đường phố đông xe qua lại. Chất lượng nét tỉa không còn ảnh hưởng bởi tay nghề của thợ tỉa viền cây. Góp phần đưa Robot vào nông nghiệp nước nhà.

\section{Tài Liệu Tham Khảo (References)}

Bui, M. V. (2004). Animal feed processing machine. Ho Chi Minh, Vietnam: Agricultural Publishing House.

Goris, K. (2005). Autonomous mobile robot: Mechanical design (Thesis). Vrije Universiteit, Brussel, Belgium.

Junyao, G., Xueshan, G., Jianguo, Z., Wei, Z., Boyu, W., \& Shilin, W. (2009). Study on the calculation method of the light mobile robot motor power. IEEE International Conference on Automation and Logistics (20002004). Shenyang, China.

Singiresu, R. S. (1986). Mechanical vibrations ( $2^{\text {nd }}$ ed.). Massachusetts, USA: Addison Wesley Longman.

Tran, D. V., Tran, V. X., Nguyen, D. T., \& Luu, N. V. (2001). Automation of production process. Ha Noi, Vietnam: Science and Technical Publishing House. 